\title{
PREPARATION OF SODIUM STRONTIUM GALACTURONATE FROM CITRUS PRODUCTS
}

\author{
By Harriet L. Frush and Horace S. Isbell
}

\section{ABSTRACT}

The present paper describes the convenient separation of galacturonic acid in the form of sodium strontium galacturonate from the hydrolyzates of citrus products, namely pectic acid, pectin, and the peel of oranges and of grapefruit. The methods are suitable for the preparation of large or small quantities of the salt, and it is believed that the preparation from pectic acid is commercially practicable.

Sodium strontium galacturonate is obtained from pectic acid in about 90 -percent yield without the use of alcohol or other organic solvent. By treatment of the salt with an equivalent quantity of aqueous sulfuric acid, a solution is obtained from which about 65 percent of the galacturonic acid may be crystallized in one crop, substantially pure. Additional crops obtained by the use of an organic solvent make the yield nearly quantitative.

Pectin is not quite so satisfactory in the process as pectic acid, but because of its educational value, the preparation of sodium strontium galacturonate from pectin might be included in a course of laboratory instruction to demonstrate the presence of galacturonic acid in pectic substances. Both orange peel and grapefruit peel may be used for the preparation of sodium strontium galacturonate, but the industrial use of these materials does not seem feasible at present on account of the large quantities of relatively expensive enzyme required for hydrolysis.

\section{CONTENTS}

I. Introduction

II. Experimental procedure

1. Preparation of sodium strontium galacturonate from pectic acid _...

2. Preparation of sodium strontium galacturonate from citrus pectin _...

3. Preparation of sodium strontium galacturonate from orange

4. Preparation of sodium strontium galacturonate from grapefruit peel_._. _._.

5. Preparation of galacturonic acid from sodium strontium galacturonate .

III. References

\section{INTRODUCTION}

The possibility of preparing vitamin $\mathrm{C}$ from galacturonates [1] ${ }^{1}$ makes important the examination of various methods and raw materials for the production of salts of galacturonic acid. In previous papers from this laboratory it has been sbown that galacturonic acid can be separated directly from the hydrolyzates of pectic substances in the form of certain new salts, particularly calcium galacturonate, sodium calcium galacturonate and sodium strontium galacturonate [2]. Some of the studies on the preparation of galacturonic acid have been conducted on hydrolyzates of beet pulp [3]. In the course of the work it was found that sodium strontium galacturonate crystal-

\footnotetext{
${ }_{1}$ Figures in brackets indicate the literature references at the end of this paper.
} 
lizes from crude hydrolyzates in higher yield than the other aforementioned salts. The present paper describes the convenient separation of galacturonic acid in the form of sodium strontium galacturonate from the hydrolyzates of citrus products, namely, pectic acid, pectin, and the peel of oranges and of grapefruit. The methods are suitable for the preparation of large or small quantities of the salt, and it is believed that the process described here is commercially practicable.

The use of pectic acid for the preparation of galacturonic acid was studied by Ehrlich [4] and by Link and coworkers [5]. Mottern and Cole [6] improved the process by employing a commercial pectic enzyme for the hydrolysis of pectic acid, and Rietz and Maclay [7] showed that the method was also applicable to the preparation of galacturonic acid from pectin. In the preparation of sodium strontium galacturonate reported here, pectic acid is the most convenient raw material for laboratory use, and the most economical at the present price of the commercial enzyme. Pectin is not quite so satisfactory in the process as pectic acid; however, the preparation of sodium strontium galacturonate from citrus pectin is described, because its educational value and simplicity are such that it might well be included in a course of laboratory instruction to demonstrate the presence of galacturonic acid as a constitutent of pectic substances.

Both orange peel and grapefruit peel may be used for the preparation of crystalline sodium strontium galacturonate. Although a considerable part of the residues from oranges and lemons is used industrially in the preparation of pectin, the residues from grapefruit have at present little use, aside from a small portion, from which naringin, the bitter glycoside of the peel, is extracted [8]. The convenient preparation of sodium strontium galacturonate from grapefruit peel is therefore significant in that it indicates a possible use for this waste product. The hydrolysis of the citrus fruit residues requires a somewhat larger amount of the enzyme than the hydrolysis of purified pectic acid or pectin. Hence the practicability of the direct utilization of the residues depends upon the cost of the enzyme in large quantities, a factor unknown at present. As mentioned in connection with the utilization of beet pulp [3], the culture media from molds grown for the production of penicillin or other substances may ulti mately provide an inexpensive source of pectic enzymes.

\section{EXPERIMENTAL PROCEDURE}

\section{PREPARATION OF SODIUM STRONTIUM GALACTURONATE FROM PECTIC ACID}

The pectic acid used in the present investigation was purchased from the California Fruit Growers' Exchange, Ontario, Calif. It contained 98 percent of galacturonic acid as determined by the carbondioxide method [9], but analyses of material purchased at various times have differed considerably. The method given here is suitable for a pectic acid having a galacturonic acid content of 95 percent or above. For a pectic acid of lower galacturonic acid content, the amounts of sodium bicarbonate and strontium carbonate should be proportionately adjusted.

A dry mixture consisting of $1,000 \mathrm{~g}$ of pectic acid, $150 \mathrm{~g}$ of sodium bicarbonate, and $100 \mathrm{~g}$ of Pectinol-46 $\mathrm{AP}^{2}$ was added in small por-

2 The pectic enzyme is manufactured by Rohm and Haas, Philadelphia, who have standardized it by dilution with diatomaceous earth to an activity arbitrarily designated 100D. 
tions, with continuous stirring, to 10 liters of water. Excessive foaming was prevented by the addition of a commercial antifoam agent. Sufficient toluene was added to cover the surface of the liquid, and the mixture was allowed to stand at $40^{\circ} \mathrm{C}$. After 1 day, $125 \mathrm{~g}$ of strontium carbonate was added in portions, and the mixture was seeded with crystals of sodium strontium galacturonate. During the period of hydrolysis the salt crystallized from the hydrolyzate. After a total of 9 days, an additional quantity of $125 \mathrm{~g}$ of strontium carbonate was added, and the mixture was allowed to stand in the refrigerator for a day. The salt was then separated by filtration, washed with cold water and dried. The crude product weighed $1,300 \mathrm{~g}$ and contained $128 \mathrm{~g}$ of water-insoluble material. To crystallize the sodium strontium galacturonate in the filtrate, $25 \mathrm{~g}$ of strontium acetate was added and the solution was evaporated under reduced pressure at a temperature below $50^{\circ} \mathrm{C}$ to a volume of about $500 \mathrm{ml}$. The concentrated solution was allowed to stand for 1 day in the refrigerator and the crystals which formed (152 g) were separated by filtration. An additional quantity of $54 \mathrm{~g}$ was obtained by concentration of the mother liquor. The three crops of crude sodium strontium galacturonate were combined and recrystallized by dissolving the salt in 12 liters of boiling water, filtering the hot solution with the aid of a decolorizing carbon, and allowing the mixture to cool. The crystals which formed were separated, washed with cold water, and dried. The filtrate was concentrated in a vacuum still, and additional crystals were thus obtained. The yield of sodium strontium galacturonate, $\mathrm{Na} \mathrm{Sr}\left(\mathrm{C}_{6} \mathrm{H}_{9} \mathrm{O}_{7}\right)_{3} 6 \mathrm{H}_{2} \mathrm{O}$, obtained without the use of an organic solvent, was $1,190 \mathrm{~g}$, or 88.6 percent of the galacturonic acid content of the pectic acid used.

The mother liquor from the first crop of crude sodium strontium galacturonate contains the residual pectic enzymes and may be used for the preparation of additional salt without the use of a new supply of the enzyme preparation. In an expermient similar to that just described, the solution which remained after separation of $1,085 \mathrm{~g}$ of sodium strontium galacturonate from the hydrolyzate of $1 \mathrm{~kg}$ of pectic acid was mixed with a second kilogram of pectic acid and $150 \mathrm{~g}$ of sodium bicarbonate. The mixture was allowed to stand, with occasional stirring, at $40^{\circ} \mathrm{C}$. After 2 days, $125 \mathrm{~g}$ of strontium carbonate was added, and after a total of 10 days, an additional quantity of $125 \mathrm{~g}$. The mixture was placed in a refrigerator for 1 day, and the crystals, which formed, were separated, washed with cold water, and air-dried. They weighed $1,400 \mathrm{~g}$. Thus the total yield of sodium strontium galacturonate obtained from $2 \mathrm{~kg}$ of pectic acid without an evaporation step, or the addition of a second quantity of enzyme, was $2,485 \mathrm{~g}$, or 92.5 percent of the galacturonic acid content of the pectic acid used. When additional pectic acid and sodium bicarbonate were added to the mother liquor, hydrolysis of the pectic acid was very slow, and it thus appeared that the enzyme had become more or less inactive. Upon the addition of a second quantity of Pectinol $(50 \mathrm{~g})$, the hydrolysis proceeded as before. Strontium carbonate was added as in the previous hydrolysis, and the resulting sodium strontium galacturonate was separated. Although in continuous operation the enzyme loses its activity and the impurities accumulate in the mother liquor, the crystallizing properties of sodium strontium galacturonate are such that the process may be continued for a considerable period before it is necessary to discard the mother liquors. 


\section{PREPARATION OF SODIUM STRONTIUM GALACTURONATE FROM CITRUS PECTIN}

A mixture of $10 \mathrm{~g}$ of dry citrus pectin, ${ }^{3} 1.25 \mathrm{~g}$ of sodium bicarbonate, and $1 \mathrm{~g}$ of Pectinol was added in portions with stirring to $100 \mathrm{ml}$ of water contained in a 200-ml Erlenmeyer flask. The mixture was protected from mold growth by the addition of $5 \mathrm{ml}$ of toluene and allowed to stand in a warm place $\left(25^{\circ}\right.$ to $\left.40^{\circ} \mathrm{C}\right)$. After 1 week, the mixture was neutralized by the addition of strontium carbonate $(3 \mathrm{~g})$ and heated to boiling to insure complete solution of the product. The hot solution was filtered with the aid of about $1 \mathrm{~g}$ of diatomaceous earth. The filtrate was concentrated in a vacuum still, at a temperature below $50^{\circ} \mathrm{C}$, to a volume of about $30 \mathrm{ml}$ and was then kept overnight in the refrigerator. The crystals of sodium strontium galacturonate, which formed, were collected on a filter, washed with cold water, and dried. The product obtained from $10 \mathrm{~g}$ of citrus pectin weighed $8.7 \mathrm{~g}$, corresponding to approximately 75 percent of the galacturonic acid content of the pectin. ${ }^{4}$

\section{PREPARATION OF SODIUM STRONTIUM GALACTURONATE FROM ORANGE PEEL}

The peels from Florida oranges were coarsely ground, and washed with cold water to remove the water-soluble constituents. The washed, moist peel contained $71.3 \mathrm{~g}$ of galacturonic acid per kilogram, as determined by the $\mathrm{CO}_{2}$ method. One kilogram of the moist peel was heated to boiling with 2 liters of water, and the mixture was then cooled to $40^{\circ} \mathrm{C}$. After the addition of $50 \mathrm{~g}$ of Pectinol and $20 \mathrm{ml}$ of toluene, the mixture was kept at a temperature of $40^{\circ} \mathrm{C}$ and stirred occasionally. "In the course of the first day, the acidity increased to about $\mathrm{pH} 3.2$ and then remained substantially constant for the remainder of the hydrolysis period. Since this value does not differ widely from the optimum for the enzyme, no adjustment of acidity was made. After 7 days, the material was transferred to a filter, and the hydrolyzate was separated from the residue. ${ }^{5}$

An analysis of the hydrolyzate gave the following results: ${ }^{6}$
Soluble solids
Volatile acid
$131 \mathrm{~g} / \mathrm{kg}$ of moist peel.
Free acid
0.048 equivalent $/ \mathrm{kg}$ of moist peel.
Copper-reducing substances
0.338 equivalent $/ \mathrm{kg}$ of moist peel.
- $115 \mathrm{~g} / \mathrm{kg}$ of moist peel.
Galacturonic acid $\left(\mathrm{CO}_{2}\right.$ method) $\ldots-\ldots 4.3 \mathrm{~g} / \mathrm{kg}$ of moist peel.
Arabinose . . . . .

The hydrolyzate from $1 \mathrm{~kg}$ of orange peel, containing $64.3 \mathrm{~g}$ of galacturonic acid, was heated to boiling, and treated with $16.4 \mathrm{~g}$ of strontium carbonate. After the strontium carbonate had reacted, the solution was cooled, and $9.3 \mathrm{~g}$ of sodium bicarbonate was added. The solution was acidified with acetic acid, and filtered with the aid of a decoloriz-

\footnotetext{
3 The sample of pectin contained 84 percent of galacturonic acid by analysis. After the first day, the acidity of the mixture should be within the $\mathrm{pH}$ range 3.5 to 4.5 . With most pectins, the proportions given here are satisfactory.

4 For student instruction, the presence of the galacturonate radical may be readily demonstrated by the following reaction discovered by Ehrlich [10]: A few milligrams of the salt, dissolved in $2 \mathrm{ml}$ of water, is treated with $5 \mathrm{ml}$ of a saturated solution of basic lead acetate. A white precipitate forms, which is soluble in an excess of the reagent. When the solution is boiled, the precipitate becomes orange, and finally brick red.

5 The addition of the pectic enzyme to citrus fruit residues causes a softening or degradation of the cell walls, which facilitates the separation of the oil in the peels. Although removal of the oil is not necessary in the preparation of sodium istrontium galacturonate, it may nevertheless be advantageous to separate it prior to filtration, or to use as a raw material, citrus fruit residues from which the oil has been removed.

6 The analytical methods are described in [3].
} 
ing carbon. The filtrate was concentrated in a vacuum still at $40^{\circ} \mathrm{C}$ to a volume of $110 \mathrm{ml}$. During the evaporation, crystals of sodium strontium galacturonate formed. The material was allowed to stand overnight in a refrigerator, and the salt was then collected on a filter, washed with a small quantity of cold water, and dried. The product, substantially pure sodium strontium galacturonate, weighed $58.8 \mathrm{~g}$. The amount corresponds to a yield of 66.7 percent, based on the galacturonic acid content of the hydrolyzate.

\section{PREPARATION OF SODIUM STRONTIUM GALACTURONATE FROM GRAPEFRUIT PEEL}

The peel of thick-skinned, seedless western grapefruit was coarsely ground in a food chopper and thoroughly washed in a bag suspended for 18 hours in running water. The moist, washed peel, containing 12.7 percent of solids, was heated to boiling with 2 parts of water. The mixture was cooled, treated with one-twentieth part of Pectinol and a small quantity of toluene, and allowed to stand at $40^{\circ} \mathrm{C}$. After 10 days, the material was filtered on a Büchner funnel, and the residue was washed with water. The combined filtrate and washings were used for analysis and for the preparation of sodium strontium galacturonate.

An analysis of the hydrolyzate gave the following results:

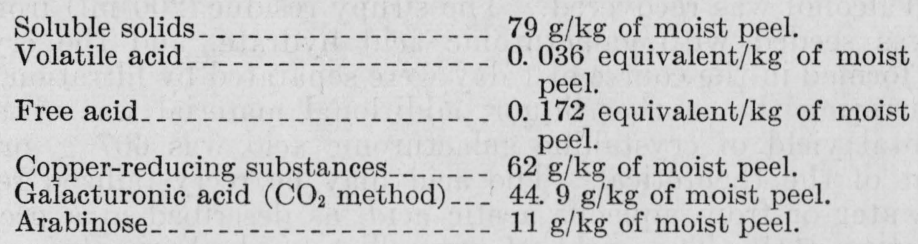

The hydrolyzate corresponding to $1 \mathrm{~kg}$ of moist peel was heated to boiling and neutralized with $11.5 \mathrm{~g}$ of strontium carbonate and $6.5 \mathrm{~g}$ of sodium bicarbonate. By filtration and concentration of the solution, $50.2 \mathrm{~g}$ of crystalline sodium strontium galacturonate was obtained. The amount corresponds to a yield of 81.6 percent, based on the galacturonic acid content of the hydrolyzate.

A similar experiment conducted on the unwashed peel, containing 19.3 percent of total solids, yielded a hydrolyzate that gave the following results:

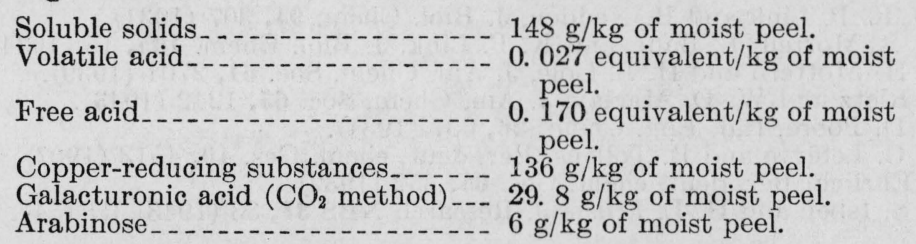

The hydrolyzate corresponding to $1 \mathrm{~kg}$ of the moist peel was treated with $7.5 \mathrm{~g}$ of strontium carbonate and $4.3 \mathrm{~g}$ of sodium bicarbonate. By concentration of the solution, $15 \mathrm{~g}$ of sodium strontium galacturonate was obtained. This amount corresponds to 36.7 percent of the galacturonic acid content of the hydrolyzate. The mother liquors contained a large amount of reducing substances which require further study. 


\section{PREPARATION OF GALACTURONIC ACID FROM SODIUM STRONTIUM GALACTURONATE}

One mole of sodium strontium galacturonate $(798.2 \mathrm{~g})$ was added with stirring to $1,500 \mathrm{ml}$ of aqueous $2 \mathrm{~N}$ sulfuric acid. ${ }^{7}$ The solution was filtered to remove the strontium sulfate, and was then concentrated to a volume of $900 \mathrm{ml}$ in a vacuum still at a temperature of $40^{\circ} \mathrm{C}$. The strontium sulfate that separated during the evaporation was removed by filtration, and the residue on the filter was washed with $100 \mathrm{ml}$ of hot water. The clear filtrate was seeded with crystalline galacturonic acid hydrate and was allowed to cool to room temperature with constant stirring. After crystallization at room temperature was substantially complete, the mixture was placed in a refrigerator for 18 hours. The crystals of galacturonic acid hydrate which formed were collected on a filter and washed with ice water. The crop of galacturonic acid monohydrate, obtained without the use of an organic solvent, weighed $407 \mathrm{~g}$ and was substantially pure. The mother liquor was concentrated in a vacuum still to a volume of $400 \mathrm{ml}$ and was then diluted with 1 liter of methyl alcohol. The alcohol was added portion-wise over the space of several hours in order to facilitate crystallization of sodium sulfate. Crystallization was induced by seeding with $\mathrm{Na}_{2} \mathrm{SO}_{4} \cdot 10 \mathrm{H}_{2} \mathrm{O}$. The salt was separated by filtration, washed with methyl alcohol, and discarded. The alcohol filtrate and wash liquor were transferred to a vacuum still and the methyl alcohol was recovered. The sirupy residue $(200 \mathrm{ml})$ from the still was seeded with galacturonic acid hydrate, and the crystals which formed in the course of 1 day were separated by filtration. By concentrating the mother liquor, additional material was obtained. The total yield of crystalline galacturonic acid was $607 \mathrm{~g}$, or 95.4 percent of the theoretical. The acid may be recrystallized readily from water or from aqueous acetic acid, as described in a previous publication [11]. The yield of crystalline acid obtained from the sodium strontium salt is considerably higher than that reported by Link and Nedden from barium galacturonate [5(b)].

\section{REFERENCES}

[1] H. S. Isbell, J. Research NBS 33, 45 (1944) RP1594.

[2] H. S. Isbell and H. L. Frush, J. Research NBS 32, 77 (1944) RP1576.

[3] H. S. Isbell and H. L. Frush, J. Research NBS 33, 389 (1944) RP1616.

[4] F. Ehrlich, Z. angew. Chem. 40, 1305 (1927).

[5] (a) K. P. Link and A. D. Dickson, J. Biol. Chem. 86, 491 (1930).

(b) K. P. Link and R. Nedden, J. Biol. Chem. 94, 307 (1931).

(c) S. Morrell, L. Baur, and K. P. Link, J. Biol. Chem. 105, i5 (1934).

[6] H. H. Mottern and H. L. Cole, J. Am. Chem. Soc. 61, 2701 (1939).

[7] E. Rietz and W. D. Maclay, J. Am. Chem. Soc. 65, 1242 (1943).

[8] H. D. Poore, Ind. Eng. Chem. 26, 637 (1934).

[9] K. U. Lefèvre and B. Tollens, Ber. deut. chem. Ges. 40, 4513 (1907).

[10] F. Ehrlich, Ber. deut. chem. Ges. 65, 352 (1932).

[11] H. S. Isbell and H. L. Frush, J. Research NBS 31, 33 (1943) RP1547.

\section{Washington, Oetober 2, 1944.}

\footnotetext{
7 For satisfactory results an excess of sulfuric acid must be avoided; a small excess of the salt is not objectionable.
} 
NATIONAL BUREAU OF STANDARDS, WASHINGTON, D. C.

Send me the Mathematical Tables marked $\times$ below. I enclose remittance to cover the cost.

\begin{tabular}{|c|c|c|c|c|}
\hline Mark X & Title of publication & $\begin{array}{l}\text { United States and } \\
\text { its possessions, } \\
\text { and countries ex- } \\
\text { tending franking } \\
\text { privilege }\end{array}$ & Other countries & Amount enclosed \\
\hline (1) & 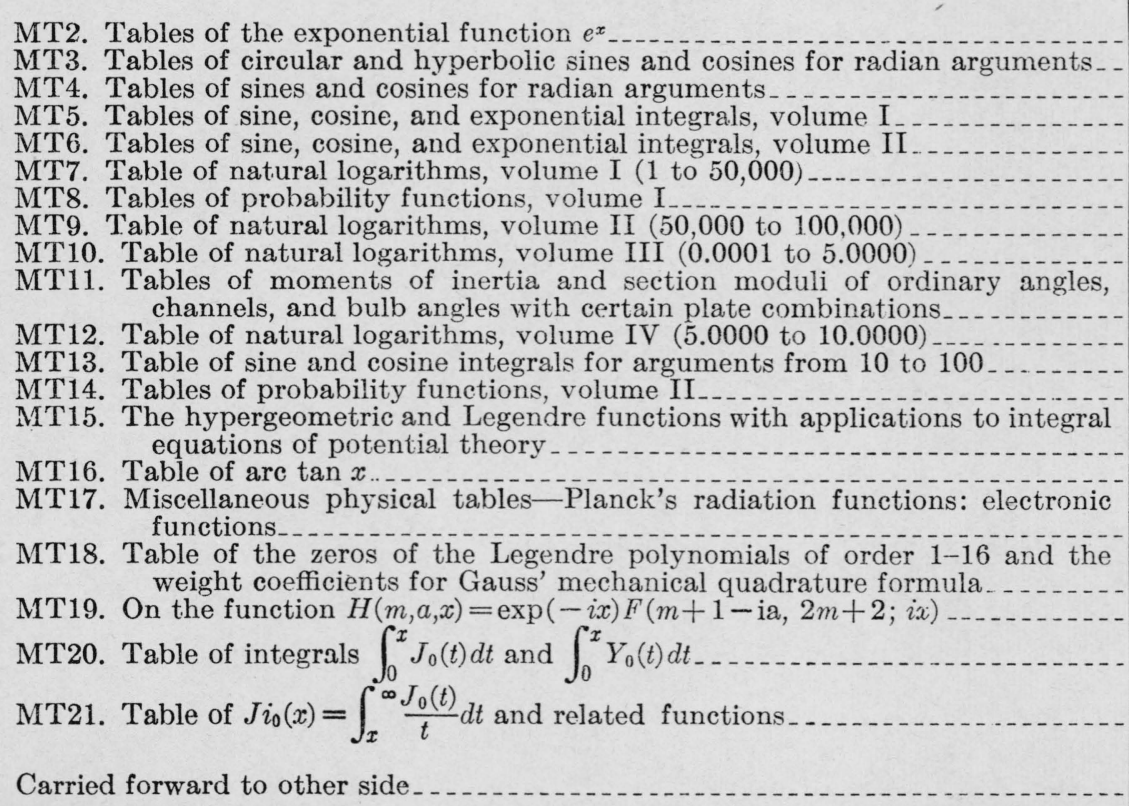 & $\begin{array}{r}\$ 2.00 \\
2.00 \\
2.00 \\
2.00 \\
2.00 \\
2.00 \\
2.00 \\
2.00 \\
2.00 \\
2.00 \\
2.00 \\
2.00 \\
2.00 \\
2.00 \\
2.00 \\
1.50 \\
.25 \\
.25 \\
.25\end{array}$ & $\begin{array}{r}\$ 2.50 \\
2.50 \\
2.50 \\
2.50 \\
2.50 \\
2.50 \\
2.50 \\
2.50 \\
2.50 \\
2.50 \\
2.50 \\
2.50 \\
2.50 \\
2.50 \\
2.50 \\
1.75 \\
\\
.30 \\
.30 \\
.30 \\
.30\end{array}$ & \begin{tabular}{|c|} 
\\
\end{tabular} \\
\hline
\end{tabular}




\begin{tabular}{|c|c|c|c|c|}
\hline Mark X & Title of publication & $\begin{array}{l}\text { United states and } \\
\text { its possessions, } \\
\text { and countries ex- } \\
\text { tending franking } \\
\text { privilege }\end{array}$ & Other countries & Amount enclosed \\
\hline - & $\begin{array}{l}\text { Brought forward from other side } \\
\text { MT22. Table of coefficients in numerical integration formulae } \\
\text { MT23. Table of Fourier coefficients } \\
\text { MT24. Coefficients for numerical differentiation with central differences } \\
\text { MT25. Seven-point Lagrangian integration formulas } \\
\text { MT26. A short table of the first five zeros of the transcendental equation, } \\
\text { MT27. Table of coefficients for inverse interpolation with central differences } J_{0}(x) Y_{0}(k x)-J_{0}(k x) Y_{0}(x)=0 \\
\text { MT28. Table of } f_{n}(x)=\frac{n !}{(x / 2)^{n}} J_{n}(x) \\
\text { MT29. Table of coefficients for inverse interpolation with advancing differences } \\
\text { Total remittance. }\end{array}$ & $\begin{array}{r}\$ 0.25 \\
.25 \\
.25 \\
.25 \\
.25 \\
.25 \\
.25 \\
.25\end{array}$ & $\begin{array}{r}.30 \\
.30 \\
30 \\
30 \\
30 \\
30 \\
30 \\
30\end{array}$ & \begin{tabular}{|l}
$\ldots$ \\
\\
\end{tabular} \\
\hline
\end{tabular}

Remittance should be in form of post-office money order, or check, and made payable to the order of the "National Bureau of Standards" in United States currency

Send to

Number and Street.

City, Zone, and State 


\section{MATHEMATICAL TABLES}

Attention is invited to a series of publications prepared by the Project for the .Computation of Mathematical Tables conducted by the Federal Works Agency, Work Projects Administration for the City of New York, under the sponsorship of the National Bureau of Standards. The tables which have been made available through the National Bureau of Standards are listed below. A list of other WPA tables obtainable elsewhere will be sent by the Bureau on request.

There is included in this list a publication on the hypergeometric and Legendre functions (MT15), prepared by the Bureau.

MT1. Table of the First Ten Powers of the Integers From 1 to 1000: (1938) VIII+80 pages; heavy paper cover. Out of print.

MT2. Tables of the Exponential Function $e^{x}$ : The ranges and intervals of the argument and the number of decimal places in the entries are given below:

$\begin{array}{rcc}\text { Range of } x & \text { Interval of } x & \text { Decimals given } \\ -2.5000 \text { to } 1.0000 & 0.0001 & 18 \\ 1.0000 \text { to } 2.5000 & .0001 & 15 \\ 2.500 \text { to } 5.000 & .001 & 15 \\ 5.00 \text { to } 10.00 & .01 & 12\end{array}$

(1939) XV+535 pages; bound in buckram, $\$ 2.00$.

MT3. Tables of Circular and Hyperbolic Sines and Cosines for Radian Arguments: Contains 9 decimal place values of $\sin x, \cos x, \sinh x$, and $\cosh x$ for $x$ (in radians) ranging from 0 to 2 at intervals of 0.0001 . (1939) XVII+ 405 pages; bound in buckram, $\$ 2.00$.

MT4. Tables of Sines and Cosines for Radian Arguments: Contains 8 decimal place values of sines and cosines for radian arguments ranging from 0 to 25 at intervals of 0.001 . (1940) XXIX +275 pages; bound in buckram, $\$ 2.00$.

MT5. Tables of Sine, Cosine, and Exponential Integrals, Volume I: Values of these functions to 9 places of decimals from 0 to 2 at intervals of 0.0001 . (1940) XXVI+ 444 pages; bound in buckram, $\$ 2.00$.

MT6. Tables of Sine, Cosine, and Exponential Integrals, Volume II: Values of these functions to 9,10 , or 11 significant figures from 0 to 10 at intervals of 0.001 with auxiliary tables. (1940) XXXVII+225 pages; bound in buckram, $\$ 2.00$.

MT7. Table of Naturai Logarithms, Volume I: Logarithms of the integers from 1 to 50,000 to 16 places of decimals. (1941) XVIII + 501 pages; bound in buckram, $\$ 2.00$.

MT8. Tables of Probability Functions, Volume I: Values of these functions to 15 places of decimals from 0 to 1 at intervals of 0.0001 and from 1 to 5.6 at intervals of 0.001 . (1941) XXVIII+302 pages; bound in buckram, $\$ 2.00$.

MT9. Table of Natural Logarithms, Volume II: Logarithms of the integers from 50,000 to 100,000 to 16 places of decimals. (1941) XVIII+501 pages; bound in buckram, $\$ 2.00$.

MT10. Table of Natural Logarithms, Volumb III: Logarithms of the decimal numbers from 0.0001 to 5.0000 , to 16 places of decimals. (1941) XVIII +501 pages; bound in buckram, $\$ 2.00$.

MT11. Tables of the Moments of Inertia and Section Moduli of Ordinary Angles, Chan. nels, and Bulb Angles with Certain Plate Combinations: (1941) XIII+197 pages; bound in green cloth. $\$ 2.00$.

MT12. Table of Natural Logarithms, Volume IV: Logarithms of the decimal numbers from 5.0000 to 10.0000 , to 16 places of decimals. (1941) XXII +506 pages; bound in buckram, $\$ 2.00$.

MT13. Table of Sine and Cosine Integrals for Arguments from 10 to 100: (1942) XXXII+185 pages; bound in buckram, $\$ 2.00$.

MT14. Tables of Probability Functions, Volume II: Values of these functions to 15 places of decimals from 0 to 1 at intervals of 0.0001 and from 1 to 7.8 at intervals of 0.001 . (1942) XXI+344 pages; bound in buckram, $\$ 2.00$.

MT15. The Hypergeòmetric and Legendre Functions With Applications to Integral Equations of Potential Theory. By Chester Snow, National Bureau of Standards. Reproduced from original handwritten manuscript. (1942) VII+319 pages, bound in heavy paper cover. $\$ 2.00$.

MT16. TABLE OF ARC TAN $x$ : Table of inverse tangents for positive values of the angle in radians. Second central differences are included for all entries. $x=[0(.001) 7(.01) 50(.1) 300(1) 2,000(10)$ 10,$000 ; 12 D$ (1942) XXV+169 pages; bound in buckram, $\$ 2.00$.

[Continued on p. 4 of cover] 


\section{[Continued from p. 3 of cover.]}

MT17. Miscellangous Physical Tables: Planck's Radiation Functions (Originally published in the Journal of the Optical Society of America, February 1940); and Electronic Functions. (1941) VII+58 pages; bound in buckram, $\$ 1.50$.

MT18. Table of the Zeros of the Legendre Polynomials of Order 1-16 and the Weight Coepricients for Gauss' Mechanical Quadrature Formula. (Reprinted from Bul. Amer. Mathematical Society, October 1942.) 5 pages, with cover, 25 cents.

MT19. On the Function $H(m, a, x)=\exp (-i x) F(m+1-i a, 2 m+2 ; i x)$; with table of the confluent hypergeometric function and its first derivative. (Reprinted from J. Math. Phys., December 1942.) 20 pages, with cover, 25 cents.

MT20. Table of Integrals $\int_{0}^{x} J_{0}(t) d t$ and $\int_{0}^{x} Y_{0}(t) d t$. (Reprinted from J. Math. Phys., May 1943.) 12 pages, with cover, 25 cents.

MT21. Table of $J i_{0}(x)=\int_{x}^{\infty} \frac{J_{0}(t)}{t} d t$ and Related Functions. (Reprinted from J. Math. Phys., June 1943.) 7 pages, with cover, 25 cents.

MT22. Table of Coefricients in Numerical Integration Formulae. (Reprinted from J. Math. Phys., June 1943.) 2 pages, with cover, 25 cents.

MT23. Table of Fourier Coefricients. (Reprinted from J. Math. Phys. Sept. 1943.) 11 pages, with cover, 25 cents.

MT24. Coefficients for Numerical Dipferentiation With Central Difrerences. (Reprinted from J. Math. Phys., Sept. 1943.) 21 pages, with cover, 25 cents.

MT25. Seven-Pont Lagrangian Integration Formulas. (Reprinted from J. Math. Phys., Dec. 1943.) 4 pages, with cover, 25 cents.

MT26. A Short Table of the First Five Zrros of the Transcendental Eouation $J_{0}(x) Y_{0}(k x)-J_{0}(k x) Y_{0}(x)=0$. (Reprinted from J. Math. Phys., Dec. 1943.) 2 pages, with cover 25 cents.

MT27. Table of Coefficients for Inverse Interpolation with Central Differences. (Re. printed from J. Math. Phys., Dec. 1943.) 15 pages, with cover. 25 cents.

MT28. TABLB of $f_{n}(x)=\frac{n !}{(x / 2)^{n}} J_{n}(x)$. (Reprinted from J. Math. Phys., Feb. 1944.) 16 pages, with cover, 25 cents.

MT29. Table of Coefricients for Inverse Interpolation with Advancing Differences. (Reprinted from J. Math. Phys., May 1944.) 28 pages, with cover, 25 cents.

Payment is required in advance. Make remittance payable to the "National Bureau of Standards" and send with order, using the blank form facing page 3 of the cover.

A mailing list is maintained for those who desire to receive announcements regarding new tables as they become available. 